\title{
Transcultural Diabetes Nutrition Algorithm: A Malaysian Application
}

\author{
Zanariah Hussein, ${ }^{1}$ Osama Hamdy, ${ }^{2}$ Yook Chin Chia, ${ }^{3}$ Shueh Lin Lim, ${ }^{4}$ \\ Santha Kumari Natkunam, ${ }^{5}$ Husni Hussain, ${ }^{6}$ Ming Yeong Tan, ${ }^{7}$ Ridzoni Sulaiman, \\ Barakatun Nisak, ${ }^{9}$ Winnie Siew Swee Chee, ${ }^{10}$ Albert Marchetti, ${ }^{11}$ \\ Refaat A. Hegazi, ${ }^{12}$ and Jeffrey I. Mechanick ${ }^{13}$ \\ ${ }^{1}$ Department of Medicine, Hospital Putrajaya, Pusat Pentadbiran Kerajaan Persekutuan, Presint 7, 62250 Putrajaya, Malaysia \\ ${ }^{2}$ Division of Endocrinology, Diabetes and Metabolism, Joslin Diabetes Center, Harvard Medical School, Boston, MA 02215, USA \\ ${ }^{3}$ Department of Medicine, University Malaya Medical Centre, Kuala Lumpur, Malaysia \\ ${ }^{4}$ Department of Medicine, Hospital Pulau Pinang, Penang, Malaysia \\ ${ }^{5}$ Department of Medicine, Hospital Tengku Ampuan Rahimah, Selangor, Malaysia \\ ${ }^{6}$ Family Medicine, Putrajaya Health Clinic, Putrajaya, Malaysia \\ ${ }^{7}$ Department of Health Care, International Medical University, Kuala Lumpur, Malaysia \\ ${ }^{8}$ Department of Dietetics and Food Services, Hospital Kuala Lumpur, Kuala Lumpur, Malaysia \\ ${ }^{9}$ Department of Nutrition and Dietetics, University Putra Malaysia, Selangor, Malaysia \\ ${ }^{10}$ Department of Nutrition and Dietetics, International Medical University, Kuala Lumpur, Malaysia \\ ${ }^{11}$ Preventive Medicine and Community Health, University of Medicine and Dentistry of New Jersey, Newark, NJ 07101, USA \\ ${ }^{12}$ Abbott Nutrition, Columbus, OH 43219, USA \\ ${ }^{13}$ Division of Endocrinology, Diabetes, and Bone Disease, Icahn School of Medicine at Mount Sinai, New York, NY 10029, USA
}

Correspondence should be addressed to Zanariah Hussein; zanariahh@hotmail.com

Received 27 June 2013; Accepted 27 September 2013

Academic Editor: Patrizio Tatti

Copyright (C) 2013 Zanariah Hussein et al. This is an open access article distributed under the Creative Commons Attribution License, which permits unrestricted use, distribution, and reproduction in any medium, provided the original work is properly cited.

\begin{abstract}
Glycemic control among patients with prediabetes and type 2 diabetes mellitus (T2D) in Malaysia is suboptimal, especially after the continuous worsening over the past decade. Improved glycemic control may be achieved through a comprehensive management strategy that includes medical nutrition therapy (MNT). Evidence-based recommendations for diabetes-specific therapeutic diets are available internationally. However, Asian patients with T2D, including Malaysians, have unique disease characteristics and risk factors, as well as cultural and lifestyle dissimilarities, which may render international guidelines and recommendations less applicable and/or difficult to implement. With these thoughts in mind, a transcultural Diabetes Nutrition Algorithm (tDNA) was developed by an international task force of diabetes and nutrition experts through the restructuring of international guidelines for the nutritional management of prediabetes and T2D to account for cultural differences in lifestyle, diet, and genetic factors. The initial evidence-based global tDNA template was designed for simplicity, flexibility, and cultural modification. This paper reports the Malaysian adaptation of the tDNA, which takes into account the epidemiologic, physiologic, cultural, and lifestyle factors unique to Malaysia, as well as the local guidelines recommendations.
\end{abstract}

\section{Introduction}

Globally, the prevalence of prediabetes and type 2 diabetes (T2D) is increasing as a consequence of social, epidemiologic, and demographic shifts, such as population aging and urbanization $[1,2]$. The majority of people with these conditions now live in low- and middle-income countries, including many Asian nations, where substantial increases in incidence 
rates are anticipated by the year 2030 [2]. According to the fourth Malaysian National Health and Morbidity Survey (NHMS IV) carried out in 2011, the prevalence of T2D in Malaysian adults $\geq 30$ years of age had risen to $20.8 \%$, affecting an estimated 2.8 million individuals [3] as compared with the third National Health and Morbidity Survey (NHMS III), which reported a prevalence of $14.9 \%$ in 2006 [4]. The heterogeneous nature of Asian populations gives rise to unique T2D features. For example, Asians tend to develop T2D at a lower body mass index (BMI), at younger age, and with a lower waist circumference than Caucasians $[5,6]$, and their course of illness is punctuated with earlier chronic complications [79] and frequent postprandial hyperglycemia [10]. These and other clinical features must be recognized and factored into lifestyle recommendations in order to tailor management to individual needs and improve the effectiveness of preventive and therapeutic efforts at the primary care level.

\section{Methods and Materials}

The universal tDNA template for patients with prediabetes and T2D was established by an international task force of experts during a two-year process that included planning and developmental meetings, evidence collection and review, consensus building, and algorithm construction and face validation [11]. The initial global template was designed for simplicity, flexibility, and cultural modification. A comparable process was used by an appointed Malaysian task force to adapt the algorithm to meet the needs of practitioners and patients in Malaysia. The regional version emerged through the modification of general tDNA recommendations to account for cultural, lifestyle, food, diet, and genetic differences that exist among the Malaysian people.

2.1. Perspectives Unique to Malaysia. Among the major ethnic groups in Malaysia, Indians (24.9\% in 2011 and 19.9\% in 2006) had the highest prevalence of T2D, followed by Malays (16.9\% in 2011 and $11.9 \%$ in 2006) and Chinese (13.8\% in 2011 and $11.4 \%$ in 2006) $[3,4]$. These epidemiologic differences could be due to the genetic makeup, diet, and cultural variants among these major ethnic groups.

The overall prevalence of abdominal obesity in Malaysia, measured by waist circumference, has been reported between $55.6 \%$ and $57.4 \%[13,14]$. Epidemiologic studies investigating abdominal obesity in Malaysia have consistently shown an ethnic trend similar to that seen in T2D with prevalence being highest among Indians (65.5-68.8\%), followed by Malays (55.1-60.6\%), Chinese (49.5-51.1\%), and other indigenous groups $(44.9-48.3 \%)[13,14]$. The prevalence of abdominal obesity is increased among patients with T2D and is observed in $75 \%$ of $\mathrm{T} 2 \mathrm{D}$ patients in Malaysia. Moreover, in the DiabCare Malaysia 2008 study, the most recent study in an ongoing initiative to monitor diabetes control in Malaysia, undesirable waist circumference was reported in a higher proportion of women $(\geq 80 \mathrm{~cm}$ in $89.4 \%)$ than men $(\geq 90 \mathrm{~cm}$ in $73.7 \%$ ) with T2D [15]. The study patients with T2D, $72 \%$ of whom were obese, had a mean BMI of $27.8 \mathrm{~kg} / \mathrm{m}^{2}$.

Glycemic control in Malaysia continues to deteriorate despite initiatives by the Ministry of Health to increase awareness and also expanded accessibility of glycosylated hemoglobin (A1c) testing across the country. The DiabCare Malaysia 2008 study reported a mean Alc of $8.66 \%$, compared with $8.0 \%$ [16] in 2003, a mean fasting glucose of $8.0 \mathrm{mmol} / \mathrm{L}$, and an elevated mean postprandial glucose of $12.7 \mathrm{mmol} / \mathrm{L}$ in Malaysians with T2D. Furthermore, only $22 \%$ of the patients achieved the glycemic target of Alc $<7 \%$, the lowest rate since 1998 [15]. Data from the online registry database Adult Diabetes Control and Management (ADCM) revealed ethnic differences in glycemic control and complication profiles among Malaysians. Chinese patients had the lowest mean Alc levels, while Malaysian Indians had the highest [17].

Only $16.4 \%$ of the Malaysian patients adhere to the dietary regimen provided by dietitians [20]. Interestingly, patients were found to adhere to the advice of "eat lots of food high in dietary fiber such as vegetables or oats" but found it difficult to eat five or more servings of fruits and vegetables per day. Self-care practices among the majority of patients with suboptimal glycemic control are obviously inadequate. A large proportion of Malaysian T2D patients consume four or more meals a day and more than two carbohydrate portions per snack [21].

The current Malaysia Clinical Practice Guidelines (CPGs) for the management of T2D contain recommendations without any specific reference to glycemia-targeted specialized nutrition (GTSN), that is, oral nutritional products that facilitate glycemic control and may be used as meal and/or snack replacements or supplements as part of the medical nutrition therapy (MNT) [18]. With the increasing prevalence of prediabetes and $\mathrm{T} 2 \mathrm{D}$ and the continued deterioration of glycemic control among patients in Malaysia, there is a clear need for a simple MNT algorithmic decision-making tool to address these issues. This paper summarizes the Malaysian adaptation of the universal tDNA template [11]. See Figure 1. Specific Southeast Asian and Asian Indian tDNA versions have also been published [22, 23].

\section{Results: Transcultural Factors for Malaysia}

3.1. Assessment of Body Composition and Risk of Disease Progression. The World Health Organization (WHO) Western Pacific Regional Office and the International Diabetes Foundation (IDF) define overweight and obesity in Asians as BMI greater than $23 \mathrm{~kg} / \mathrm{m}^{2}$ and $25 \mathrm{~kg} / \mathrm{m}^{2}$, respectively [24]. Lower cutoff values are required for Asian populations because Asians generally have a higher percentage of intraabdominal fat compared with Caucasians of the same age, sex, and BMI [25]. Furthermore, Asian populations have higher cardiovascular and T2D risk factors than Caucasians at any BMI level $[25,26]$, thereby highlighting the rationale for defining Asian-specific cutoff values for anthropometric measures.

The Malaysian CPG for the management of obesity categorizes overweight as BMI of $23.0-27.4 \mathrm{~kg} / \mathrm{m}^{2}$ and obesity as BMI of $27.5 \mathrm{~kg} / \mathrm{m}^{2}$ and above [28]. Waist circumference cutoff values for abdominal obesity are $90 \mathrm{~cm}$ for men and $80 \mathrm{~cm}$ for women [24]. Similarly, these cutoff values are also found in the CPG for the management of T2D in Malaysia [12] and are used as the standard throughout this paper. 


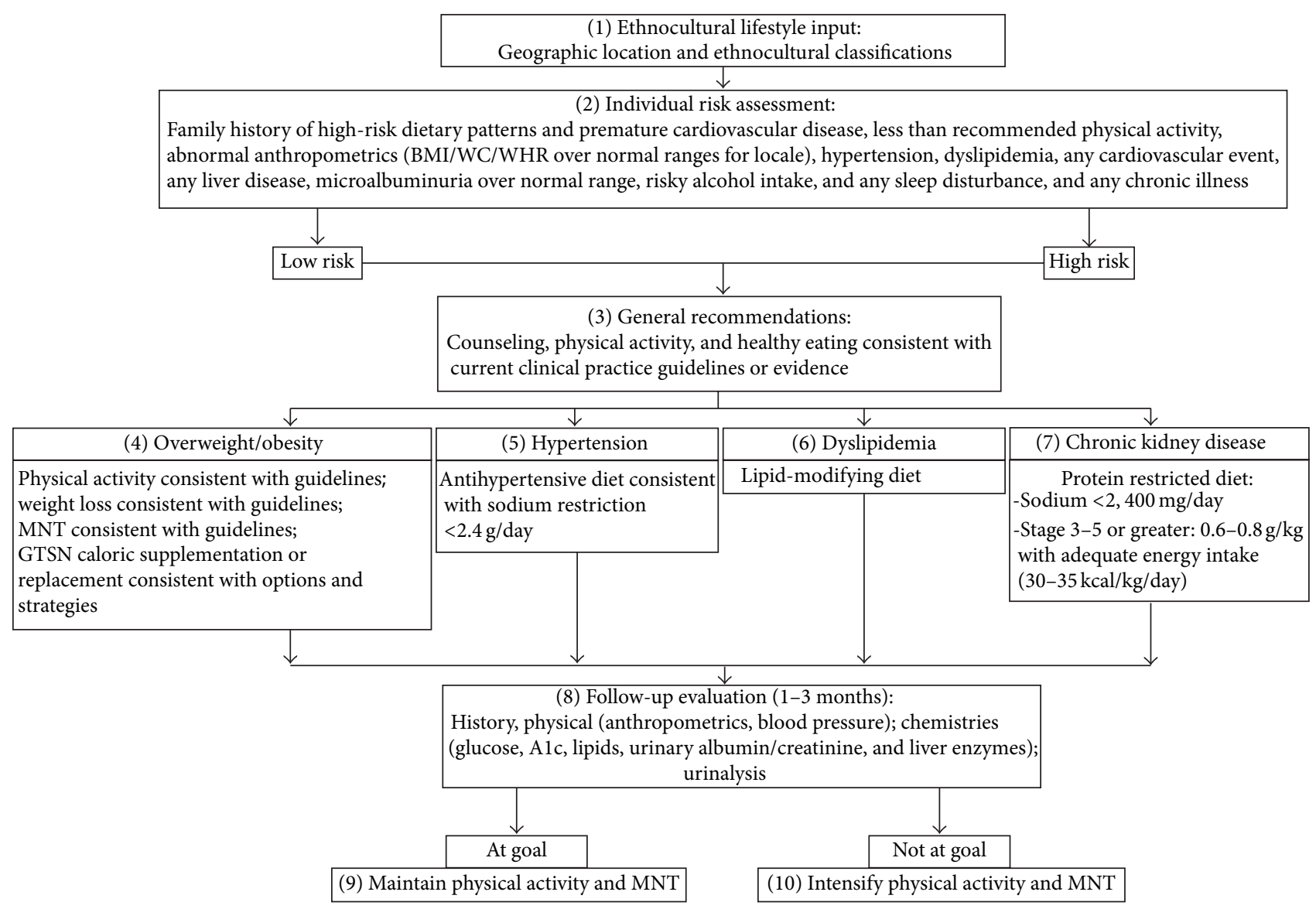

See text and tables throughout this report for additional information and clarifications

FIgURE 1: Transcultural Diabetes Nutrition Algorithm (tDNA): Malaysian application.

3.2. Physical Activity in T2D Management. Physical activity and exercise have been shown to lower blood glucose levels, improve glucose and insulin utilization, and improve carbohydrate metabolism $[29,30]$. Benefits of physical activity have been demonstrated in both Caucasian and Asian patients with T2D [31-34]. The Malaysian CPG for the management of $\mathrm{T} 2 \mathrm{D}$ recommends physical activity as an integral feature in every stage of T2D management [12]. These recommendations are echoed in the Malaysian tDNA application (Table 1).

3.3. MNT and Weight Loss in T2D Management. MNT plays an integral role in T2D management and indeed is recommended by the American Diabetes Association as an important component of individual weight loss programs for T2D patients [35]. The benefits of MNT on glycemic control in Asians with prediabetes and T2D have been demonstrated in clinical trials [36-39]. On-site registered dietitian-led management of MNT has been shown to improve glycemic control in poorly-managed patients with T2D in primary care clinics in Taiwan. Patients with Alc levels $\geq 7 \%$ who received on-site diabetic self-management education had significantly greater improvements in fasting plasma glucose and Alc levels after one year than control subjects or subjects with
Alc levels <7\% [36]. A lifestyle intervention that includes MNT was found to be effective in preventing or delaying the development of T2D in middle-aged Japanese patients with impaired glucose tolerance [40, 41].

The Malaysian Dietitians' Association (MDA) has formed an expert committee, comprising dietitians from primary care, hospitals, and academia, to compose MNT recommendations for T2D. The first version was published in 2005 [42] and updated in 2013 [43]. Building on the MNT guidelines recommended by the MDA, the Malaysian CPG for the management of $\mathrm{T} 2 \mathrm{D}$, and taking into consideration similar Malaysian CPGs for hypertension and dyslipidemia, this panel recommends the nutritional considerations outlined in Table $2[12,18,19]$.

Weight loss is an important therapeutic objective for T2D patients to reduce insulin resistance. Moderate weight loss of just $5-10 \%$ of body weight in patients with T2D has been shown to decrease insulin resistance and improve other metabolic risk factors [38, 44, 45]. GTSN formulae are a component of MNT that contain nutrients to facilitate weight management and glycemic control. These formulae are available in Malaysia and may be utilized with nutritional counseling as meal and/or snack replacements for overweight and obese patients and those with suboptimal glycemic 
TABLE 1: Physical activity guidelines for the management of type 2 diabetes $^{\mathrm{a}}[12]$.

\begin{tabular}{|c|c|c|}
\hline \multirow{3}{*}{ All patients } & Frequency & $\begin{array}{l}\text { Exercise } 5 \text { days a week with } \\
\text { no more than } 2 \text { consecutive } \\
\text { days without physical } \\
\text { exercise }\end{array}$ \\
\hline & $\begin{array}{l}\text { Intensity and } \\
\text { type }\end{array}$ & $\begin{array}{l}\text { (i) Moderate-intensity } \\
\text { activities include walking } \\
\text { down stairs, cycling, fast } \\
\text { walking, doing heavy } \\
\text { laundry, ballroom dancing } \\
\text { (slow), noncompetitive } \\
\text { badminton, and } \\
\text { low-impact aerobics } \\
\text { (ii) Vigorous activities } \\
\text { include jogging, climbing } \\
\text { stairs, football, squash, } \\
\text { tennis, swimming, jumping } \\
\text { rope, and basketball }\end{array}$ \\
\hline & Duration & $\begin{array}{l}150 \text { min per week of } \\
\text { moderate-intensity aerobic } \\
\text { physical activity and/or at } \\
\text { least } 90 \text { min per week of } \\
\text { vigorous aerobic physical } \\
\text { activity }\end{array}$ \\
\hline \multicolumn{2}{|c|}{$\begin{array}{l}\text { Overweight or obese patients } \\
(\mathrm{BMI}>23)\end{array}$} & $\begin{array}{l}\text { Gradually increase physical } \\
\text { activity to } 60-90 \text { minutes } \\
\text { daily for long-term major } \\
\text { weight loss }\end{array}$ \\
\hline
\end{tabular}

BMI: body mass index.

${ }^{\text {a }}$ Patients should be assessed for complications that may preclude vigorous exercise. Age and previous physical activity level should be considered.

TABLE 2: Nutrition guidelines for the management of type 2 diabetes $[12,18,19]$.

\begin{tabular}{ll}
\hline Calories & $\begin{array}{l}\text { For overweight and obese individuals, a reduced } \\
\text { calorie diet of } 20-25 \mathrm{kcal} / \mathrm{kg} \text { body weight is } \\
\text { recommended to achieve a weight loss of 5-10\% } \\
\text { of initial body weight over a 6-month period }\end{array}$ \\
Carbohydrate & $\begin{array}{l}45-60 \% \text { daily energy intake } \\
\text { 15-20\% daily energy intake }\end{array}$ \\
Protein & $25-35 \%$ daily energy intake \\
Saturated fat & Less than 7\% of total calories \\
Cholesterol & Less than 200 mg/day \\
Fiber* & $20-30$ g/day \\
Sodium & $<2,400 \mathrm{mg} /$ day \\
\hline
\end{tabular}

*Should be derived predominantly from foods rich in complex carbohydrates including grains (especially whole grains), fruits and vegetables.

control, including persons with high insulin requirements. These formulae are also indicated as a supplementary nutrition for patients with diabetes and acute concurrent illness who are unable to maintain optimal nutrition due to reduced appetite and calorie intake. Recommendations for the use of meal replacements will be incorporated in the revised MNT guidelines from the MDA.
3.4. Nutritional Management of Patients with Concomitant Hypertension, Dyslipidemia, and/or Chronic Kidney Disease (CKD). Data from the ADCM's online registry database showed that as many as $57 \%$ of the Malaysian patients with T2D experience concomitant hypertension [46]. Among the ethnic groups in Malaysia, more Malay patients (62.3\%) have concomitant hypertension than Chinese (19.6\%) or Indian (17.0\%) patients. In patients with $\mathrm{T} 2 \mathrm{D}$, hypertension is defined as blood pressure $>130 / 80 \mathrm{mmHg}$ on two readings 23 weeks apart [12]. Pharmacotherapy for hypertension should be initiated in patients with T2D when the blood pressure is persistently $>130 \mathrm{mmHg}$ systolic and/or $>80 \mathrm{mmHg}$ diastolic [12]. For patients with concomitant hypertension, salt intake should be restricted to $<6 \mathrm{~g} /$ day (sodium $2 \mathrm{~g}$ ) [18].

The ADCM also revealed that as many as $38 \%$ of the patients with T2D in Malaysia suffer from concomitant dyslipidemia [47]. Malays were more likely to have uncontrolled low-density lipoprotein cholesterol (LDL-C) and triglycerides compared with Chinese and Indians; however, Indians were twice as likely to have inadequate high-density lipoprotein cholesterol compared with Malays [47]. A recent study that investigated the ethnic differences in lipid metabolism among Malaysian patients with T2D demonstrated that Malays had significantly higher serum levels of glycoxidation and lipoxidation products compared with those of Chinese and Indian patients [48]. For T2D patients with dyslipidemia, lifestyle modification focusing on the reduction of saturated fat ( $<7 \%$ of total calories), trans fat (avoid), and cholesterol $(<200 \mathrm{mg} /$ day) intake has been recommended $[12,19]$. In accordance with the Malaysian CPG for dyslipidemia, patients over the age of 40 without overt cardiovascular disease (CVD) should be treated with lipid lowering drugs, regardless of the baseline LDL-C levels, while all patients with overt CVD, irrespective of age, should be treated with lipid lowering drugs [19].

For T2D patients with concomitant CKD, limited protein intake and daily sodium $<2400 \mathrm{mg}$ are recommended. For those with CKD stages $3-5$, daily protein should be limited to $0.6-0.8 \mathrm{~g} / \mathrm{kg}$ in a diet with adequate energy intake (30-35 $\mathrm{kcal} / \mathrm{kg} /$ day) [49].

\section{Conclusions}

The following recommendations, statements, figures, tables, and graphs represent the conclusions of the Malaysian transcultural Diabetes Nutrition Algorithm (tDNA) task force and constitute the current Malaysian tDNA application, which accommodates local differences in lifestyle, foods, and customs and incorporates established local Clinical Practice Guidelines (CPGs) to meet the needs and preferences of type 2 diabetes (T2D) patients in Malaysia.

Recommendation 1. Medical nutrition therapy (MNT) is an integral component of the management of T2D and must be prioritized in view of poor glycemic control among patients in Malaysia. Individualized care plans are essential 
TABLE 3: Glycemia-targeted specialized nutrition (GTSN) for the management of prediabetes and type 2 diabetes.

\begin{tabular}{|c|c|c|}
\hline \multicolumn{2}{|c|}{$\begin{array}{l}\text { Overweight }\left(\mathrm{BMI}>23 \mathrm{~kg} / \mathrm{m}^{2}\right) \text { or } \\
\text { obese }\left(\mathrm{BMI}>27.5 \mathrm{~kg} / \mathrm{m}^{2}\right)\end{array}$} & $\begin{array}{l}\text { Use meal and/or snack } \\
\text { replacements }{ }^{\mathrm{a}} \text { as part of a } \\
\text { meal plan to reduce total } \\
\text { calorie intake } \\
\text { (i) Calorie reduction of } \\
500-1000 \text { calories per day } \\
\text { (to lose } 0.5-1.0 \text { kg per } \\
\text { week), using } 1-2 \text { servings of } \\
\text { a GTSN formula }{ }^{\text {b }} \text { to replace } \\
250-500 \text { calories from } \\
\text { meals } \\
\text { (ii) Reassess every } \\
1-3 \text { months }\end{array}$ \\
\hline \multirow[t]{2}{*}{$\begin{array}{l}\text { Normal weight } \\
\left(\mathrm{BMI} 18-23 \mathrm{~kg} / \mathrm{m}^{2}\right)\end{array}$} & $\begin{array}{c}\text { Controlled } \\
\text { diabetes } \\
\left(\mathrm{Alc} \leq 6.5 \%^{\mathrm{c}}\right)\end{array}$ & $\begin{array}{l}\text { The use of meal } \\
\text { replacements should be } \\
\text { based on clinical judgment } \\
\text { and individual assessment }{ }^{\mathrm{d}}\end{array}$ \\
\hline & $\begin{array}{l}\text { Uncontrolled } \\
\text { diabetes } \\
\left(\text { Alc }>6.5 \%{ }^{c}\right)\end{array}$ & $\begin{array}{l}\text { Use } 1-2 \text { servings of a GTSN } \\
\text { formula per day to be } \\
\text { incorporated into a meal } \\
\text { plan }\end{array}$ \\
\hline \multicolumn{2}{|c|}{ Underweight $\left(\mathrm{BMI}<18 \mathrm{~kg} / \mathrm{m}^{2}\right)$} & $\begin{array}{l}\text { Use 1-3 servings of a GTSN } \\
\text { formula per day as } \\
\text { supplementation based on } \\
\text { clinical judgment and } \\
\text { individual assessment of } \\
\text { desired rate of weight gain } \\
\text { and clinical tolerance }\end{array}$ \\
\hline
\end{tabular}

BMI: body mass index; Alc: glycosylated hemoglobin; GTSN: glycemiatargeted specialized nutrition.

Recommendations were rated and assigned numerical and alphabetical descriptors according to levels of scientific substantiation provided by the 2010 American Association of Clinical Endocrinologists protocol for the development of Clinical Practice Guidelines [27].

${ }^{\mathrm{a}} \mathrm{Meal}$ and snack replacements are nutritional products used as replacement for meals or snacks to replace calories in the diet. It is suggested that products used should meet the American Diabetes Association nutritional guidelines.

${ }^{\mathrm{b}}$ Glycemia-targeted specialized nutrition formulas are complete and balanced products with at least 200 calories per serving used as part of a meal plan to help control calorie intake and achieve glycemic control.

${ }^{\mathrm{c}}$ Glycemic (Alc) targets should be individualized for each patient based on local CPGs.

${ }^{d}$ To avoid hypoglycemia or postprandial hyperglycemia, individuals who may have muscle mass and/or function loss and/or micronutrient deficiency may benefit from a nutrition supplement. Individuals who need support with weight maintenance and/or a healthy meal plan could benefit from meal replacement.

in order to increase adherence and compliance with MNT recommendations.

Recommendation 2. Personalized nutrition counseling by a dietitian is recommended and should be individualized according to personal nutritional needs, concomitant disease, severity of T2D, cultural preferences, and patient cooperation. If access to a dietitian is not possible, all newly diagnosed patients should receive basic nutrition and dietary counseling from either doctors or diabetes educators.
Recommendation 3. Values for body mass index (BMI) cutoffs in the Malaysian CPGs are recommended for use in the Malaysian tDNA.

Recommendation 4. The Malaysian CPG for the management of T2D recommends physical activity as an integral feature in every stage of T2D management [12]. These recommendations are adopted in the Malaysian tDNA (Table 1).

Recommendation 5. Overweight and obese individuals should achieve a weight loss of 5-10\% of the initial body weight over a 6-month period (Table 2).

Recommendation 6. The nutritional recommendations outlined in Table 2 (adapted from the Malaysian Dietitians' Association's MNT guidelines and the Malaysian CPG for the management of T2D) should be implemented as part of the Malaysian tDNA.

Recommendation 7. Patients with T2D and concomitant hypertension should limit salt intake to $<6 \mathrm{~g} /$ day (sodium $2 \mathrm{~g})$. Those with concomitant chronic kidney disease (CKD) should limit protein intake, especially those with CKD stages $3-5$ (daily protein of $0.6-0.8 \mathrm{~g} / \mathrm{kg}$ with adequate energy intake of $30-35 \mathrm{kcal} / \mathrm{kg} / \mathrm{day})$.

Recommendation 8. Lifestyle modification focusing on the reduction of saturated fat ( $<7 \%$ of total calories) and cholesterol ( $<200 \mathrm{mg} /$ day), as well as the avoidance of trans-fat, is recommended for patients with $\mathrm{T} 2 \mathrm{D}$ and concomitant dyslipidemia.

Recommendation 9. The use of meal replacements should be based on clinical judgment and individual assessment. For patients who are overweight, meal and/or snack replacements are recommended as part of meal plans to reduce total calorie intake (Table 3 ). For patients of normal weight with uncontrolled T2D, 1-2 servings of a GTSN formula per day, incorporated into a meal plan as meal or snack replacement, are recommended. For underweight individuals, 13 servings of a GTSN formula per day are recommended as supplementation based on the clinical judgment and individual assessment of desired rate of weight gain and clinical tolerance.

Recommendation 10. To provide support and motivate patients to comply with MNT, monthly follow-ups are recommended for patients with poorly-controlled T2D and for those who are at high risk of complications. For patients with well-controlled T2D, regular follow-up every 3 months is recommended.

\section{Disclosures}

Zanariah Hussein has received consulting fees from Abbott Nutrition, Novo Nordisk, AstraZeneca, and Boehringer Ingelheim. Osama Hamdy has served as a consultant for Abbott Nutrition and a speaker for Amylin/Eli Lilly. Yook Chin Chia has received honorarium for lectures from Pfizer, Servier, 
AstraZeneca, Sanofi-Aventis, Reckitt Benckiser, GlaxoSmithKline, and Sandoz. Shueh Lin Lim has received honorarium for lectures from Merck Sharp Dohme, Eli Lilly, Abbott, Novo Nordisk, Novartis, AstraZeneca, Merck Serono, and SanofiAventis. Santha Kumari has no conflict of interests to declare. Husni Hussain has received honorarium for lectures from Merck Serono, Sanofi-Aventis, and ASP Medical Clinic Sdn Bhd. Ming Yeong Tan has received consulting fee from Abbott Nutrition and honorarium for lectures from Roche Diagnostics, Abbott Nutrition, Merck Sharp Dohme, and Merck Serono. Ridzoni Sulaiman, Barakatun Nisak, and Winnie Siew Swee Chee have received consulting fee or honorarium from Abbott Nutrition. Refaat A. Hegazi is employed by Abbott Nutrition; the material presented in this paper is based on the best-known clinical evidence and is not affected by this financial relationship. Albert Marchetti has received financial support for research and the development of educational materials from Eli Lilly, Takeda, GlaxoSmithKline, BristolMyers Squibb, and Abbott Nutrition. Jeffrey Mechanick has received financial support for the development of educational presentations from Abbott Nutrition. He has received financial support for consultancy and for writing and reviewing the paper from Abbott Nutrition. He has received fees for participation in review activities such as data monitoring boards, statistical analysis, and endpoint committees from Abbott Nutrition International. He has received funding for travel and accommodations from Abbott Nutrition.

\section{Acknowledgments}

The content of this paper was created and enriched solely by the authors, tDNA task force members, through a process of the ongoing literature searches, independent contributions and reviews, and group interactions for consensus. Financial support was provided by Abbott Nutrition International through an educational grant. Editorial support was provided by Mediconnexions Consulting Sdn Bhd.

\section{References}

[1] J. E. Shaw, R. A. Sicree, and P. Z. Zimmet, "Global estimates of the prevalence of diabetes for 2010 and 2030," Diabetes Research and Clinical Practice, vol. 87, no. 1, pp. 4-14, 2010.

[2] D. R. Whiting, L. Guariguata, C. Weil, and J. Shaw, "IDF Diabetes Atlas: global estimates of the prevalence of diabetes for 2011 and 2030," Diabetes Research and Clinical Practice, vol. 94, no. 3, pp. 311-321, 2011.

[3] I. M. Feisul, "Current burden of diabetes in Malaysia," in Proceedings of the 1st National Institutes of Health (NIH) Scientific Meeting, Selangor, Malaysia, June 2012.

[4] G. R. Letchuman, W. M. Wan Nazaimoon, W. B. Wan Mohamad et al., "Prevalence of diabetes in the Malaysian National Health Morbidity Survey III 2006," The Medical Journal of Malaysia, vol. 65 , no. 3, pp. 180-186, 2010.

[5] R. Huxley, W. P. T. James, F. Barzi et al., "Ethnic comparisons of the cross-sectional relationships between measures of body size with diabetes and hypertension," Obesity Reviews, vol. 9, no. 1, pp. 53-61, 2008.
[6] K.-H. Yoon, J.-H. Lee, J.-W. Kim et al., "Epidemic obesity and type 2 diabetes in Asia," The Lancet, vol. 368, no. 9548, pp. 1681$1688,2006$.

[7] S.-C. Chiang, J.-K. Lee, C.-H. Chen et al., "Justifying the high prevalence of microalbuminuria for type 2 diabetic patients in Taiwan with conditional probability approach-a DEMAND II Study," Journal of the Chinese Medical Association, vol. 74, no. 1, pp. 3-10, 2011.

[8] A. Y. T. Wu, N. C. T. Kong, F. A. De Leon et al., "An alarmingly high prevalence of diabetic nephropathy in Asian type 2 diabetic patients: the MicroAlbuminuria Prevalence (MAP) Study," Diabetologia, vol. 48, no. 1, pp. 17-26, 2005.

[9] L.-M. Chuang, S. T. Tsai, B. Y. Huang, and T. Y. Tai, “The status of diabetes control in Asia-a cross-sectional survey of 24317 patients with diabetes mellitus in 1998," Diabetic Medicine, vol. 19, no. 12, pp. 978-985, 2002.

[10] J.-S. Wang, S.-T. Tu, I.-T. Lee et al., "Contribution of postprandial glucose to excess hyperglycaemia in Asian type 2 diabetic patients using continuous glucose monitoring," Diabetes/Metabolism Research and Reviews, vol. 27, no. 1, pp. 79-84, 2011.

[11] J. I. Mechanick, A. E. Marchetti, C. Apovian et al., "Diabetesspecific nutrition algorithm: a transcultural program to optimize diabetes and prediabetes care," Current Diabetes Reports, vol. 12, no. 2, pp. 180-194, 2012.

[12] Ministry of Health Malaysia, "Malaysian Clinical Practice Guidelines for the Management of Type 2 Diabetes Mellitus," 2009, http://www.acadmed.org.my/.

[13] W. N. W. Mohamud, A. A.-S. Ismail, A. S. M. Khir et al., "Prevalence of metabolic syndrome and its risk factors in adult Malaysians: results of a nationwide survey," Diabetes Research and Clinical Practice, vol. 96, no. 1, pp. 91-97, 2012.

[14] M. Zaki, Z. Robaayah, S. P. Chan, M. Vadivale, and T. O. Lim, "Malaysia Shape of the Nation (MySoN): a primary care based study of abdominal obesity in Malaysia," The Medical Journal of Malaysia, vol. 65, pp. 143-149, 2010.

[15] M. Mafauzy, Z. Hussein, and S. P. Chan, "The status of diabetes control in Malaysia: results of diabcare 2008," Medical Journal of Malaysia, vol. 66, no. 3, pp. 175-181, 2011.

[16] M. Mohamed, "An audit on diabetes management in Asian patients treated by specialists: the Diabcare-Asia 1998 and 2003 studies," Current Medical Research and Opinion, vol. 24, no. 2, pp. 507-514, 2008.

[17] B. H. Chew, I. Mastura, P. Y. Lee, T. Sri Wahyu, A. T. Cheong, and A. Zaiton, "Ethnic differences in glycaemic control and complications: the adult diabetes control and management (ADCM), Malaysia," Medical Journal of Malaysia, vol. 66, no. 3, pp. 244-248, 2011.

[18] Ministry of Health Malaysia, "Malaysian Clinical Practice Guidelines for the Management of Hypertension (3rd Edition)," 2008, http://www.acadmed.org.my/.

[19] "Ministry of Health MalaysiaClinical Practice Guidelines on Management of Dyslipidaemia 3rd Edition," 2004, http://www .acadmed.org.my/.

[20] S. L. Tan, S. Juliana, and H. Sakinah, "Dietary compliance and its association with glycemic control among poorly controlled type 2 diabetic outpatients in Hospital Universiti Sains Malaysia," Malaysian Journal of Nutrition, vol. 17, no. 3, pp. 287-299, 2011.

[21] M. Y. Tan and J. Magarey, "Self-care practices of Malaysian adults with diabetes and sub-optimal glycaemic control," Patient Education and Counseling, vol. 72, no. 2, pp. 252-267, 2008. 
[22] S. R. Joshi, V. Mohan, S. S. Joshi, J. I. Mechanick, and A. Marchetti, "Transcultural diabetes nutrition therapy algorithm: the Asian indian application," Current Diabetes Reports, vol. 12, no. 2, pp. 204-212, 2012.

[23] H.-Y. Su, M.-W. Tsang, S.-Y. Huang, J. I. Mechanick, W. H.H. Sheu, and A. Marchetti, "Transculturalization of a diabetesspecific nutrition algorithm: Asian application," Current Diabetes Reports, vol. 12, no. 2, pp. 213-219, 2012.

[24] World Health Organization, International Association for the Study of Obesity, and International Obesity Taskforce. The AsiaPacific Perspective: Redefining Obesity and Its Treatment, Health Communications, Sydney, Australia, 2000.

[25] WHO Expert Consultation, "Appropriate body-mass index for Asian populations and its implications for policy and intervention strategies," The Lancet, vol. 363, no. 9403, pp. 157-163, 2004.

[26] S. Low, M. C. Chin, M. Stefan, D. Heng, and M. DeurenbergYap, "Rationale for redefining obesity in asians," Annals of the Academy of Medicine Singapore, vol. 38, no. 1, pp. 66-69, 2009.

[27] J. I. Mechanick, P. M. Camacho, R. H. Cobin et al., "American Association of Clinical Endocrinologists protocol for standardized production of clinical practice guidelines-2010 update," Endocrine Practice, vol. 16, no. 2, pp. 270-283, 2010.

[28] Ministry of Health Malaysia, "Clinical Practice Guidelines on Management of Obesity," 2004, http://www.acadmed.org.my/.

[29] M. Riddell and B. A. Perkins, "Exercise and glucose metabolism in persons with diabetes mellitus: perspectives on the role for continuous glucose monitoring," Journal of Diabetes Science and Technology, vol. 3, no. 4, pp. 914-923, 2009.

[30] R. J. Sigal, G. P. Kenny, D. H. Wasserman, and C. CastanedaSceppa, "Physical activity/exercise and type 2 diabetes," Diabetes Care, vol. 27, no. 10, pp. 2518-2539, 2004.

[31] N. G. Boulé, E. Haddad, G. P. Kenny, G. A. Wells, and R. J. Sigal, "Effects of exercise on glycemic control and body mass in type 2 diabetes mellitus: a meta-analysis of controlled clinical trials," Journal of the American Medical Association, vol. 286, no. 10, pp. 1218-1227, 2001.

[32] G. Li, P. Zhang, J. Wang et al., "The long-term effect of lifestyle interventions to prevent diabetes in the China Da Qing Diabetes Prevention Study: a 20-year follow-up study," The Lancet, vol. 371, no. 9626, pp. 1783-1789, 2008.

[33] T. S. Church, S. N. Blair, S. Cocreham et al., "Effects of aerobic and resistance training on hemoglobin Alc levels in patients with type 2 diabetes: a randomized controlled trial," Journal of the American Medical Association, vol. 304, no. 20, pp. 22532262, 2010.

[34] D. Umpierre, P. A. B. Ribeiro, C. K. Kramer et al., "Physical activity advice only or structured exercise training and association with $\mathrm{HbAlc}$ levels in type 2 diabetes: a systematic review and meta-analysis," Journal of the American Medical Association, vol. 305, no. 17, pp. 1790-1799, 2011.

[35] American Diabetes Association, "Standards of medical care in diabetes-2013," Diabetes Care, vol. 36, supplement 1, pp. S11S66, 2013.

[36] M.-C. Huang, C.-C. Hsu, H.-S. Wang, and S.-J. Shin, "Prospective randomized controlled trial to evaluate effectiveness of registered dietitian-led diabetes management on glycemic and diet control in a primary care setting in Taiwan," Diabetes Care, vol. 33, no. 2, pp. 233-239, 2010.

[37] K.-W. Liang, W.-J. Lee, I.-T. Lee et al., "Persistent elevation of paraoxonase-1 specific enzyme activity after weight reduction in obese non-diabetic men with metabolic syndrome," Clinica Chimica Acta, vol. 412, no. 19-20, pp. 1835-1841, 2011.
[38] W. H.-H. Sheu, T.-M. Chang, W.-J. Lee et al., "Effect of weight loss on proinflammatory state of mononuclear cells in obese women," Obesity, vol. 16, no. 5, pp. 1033-1038, 2008.

[39] H.-F. Lang, C.-Y. Chou, W. H.-H. Sheu, and J.-Y. Lin, "Weight loss increased serum adiponectin but decreased lipid levels in obese subjects whose body mass index was lower than $30 \mathrm{~kg} / \mathrm{m}^{2}$ ,"Nutrition Research, vol. 31, no. 5, pp. 378-386, 2011.

[40] N. Sakane, J. Sato, K. Tsushita et al., "Prevention of type 2 diabetes in a primary healthcare setting: three-year results of lifestyle intervention in Japanese subjects with impaired glucose tolerance," BMC Public Health, vol. 11, article 40, 2011.

[41] T. Saito, M. Watanabe, J. Nishida et al., "Lifestyle modification and prevention of type 2 diabetes in overweight Japanese with impaired fasting glucose levels: a randomized controlled trial," Archives of Internal Medicine, vol. 171, no. 15, pp. 1352-1360, 2011.

[42] Malaysian Dietitians' Association, "Medical Nutrition Therapy Guidelines for Type 2 Diabetes," 2005.

[43] Malaysian Dietitians' Association, "Medical Nutrition Therapy Guidelines for Type 2 Diabetes," 2013.

[44] G. Mazzali, V. Di Francesco, E. Zoico et al., "Interrelations between fat distribution, muscle lipid content, adipocytokines, and insulin resistance: effect of moderate weight loss in older women," American Journal of Clinical Nutrition, vol. 84, no. 5, pp. 1193-1199, 2006.

[45] K. Esposito, A. Pontillo, C. Di Palo et al., "Effect of weight loss and lifestyle changes on vascular inflammatory markers in obese women: a randomized trial," Journal of the American Medical Association, vol. 289, no. 14, pp. 1799-1804, 2003.

[46] B. H. Chew, M. Ismail, S. Shariff-Ghazali et al., "Determinants of uncontrolled hypertension in adult type 2 diabetes mellitus: an analysis of the Malaysian diabetes registry 2009," Cardiovascular Diabetology, vol. 11, no. 1, p. 54, 2012.

[47] B. H. Chew, M. Ismail, P. Y. Lee et al., "Determinants of uncontrolled dyslipidaemia among adult type 2 diabetes in Malaysia: the Malaysian Diabetes Registry 2009," Diabetes Research and Clinical Practice, vol. 96, no. 3, pp. 339-347, 2012.

[48] K. A.-A. Ahmed, S. Muniandy, I. S. Ismail, R. S. Ali, and Z. H. Alhamodi, "Evaluation of $\mathrm{Ne}$-(carboxymethyl)lysine and lipid peroxidation in multiethnic Malaysian subjects with type 2 diabetes mellitus," Scientific Research and Essays, vol. 6, no. 9, pp. 1957-1962, 2011.

[49] Ministry of Health Malaysia, "Clinical Practice Guidelines on Management of Chronic Kidney Disease in Adults," 2011. 


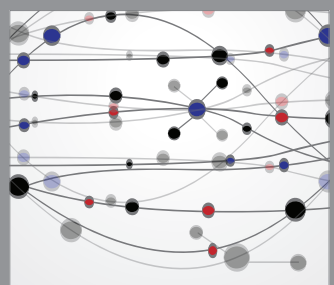

The Scientific World Journal
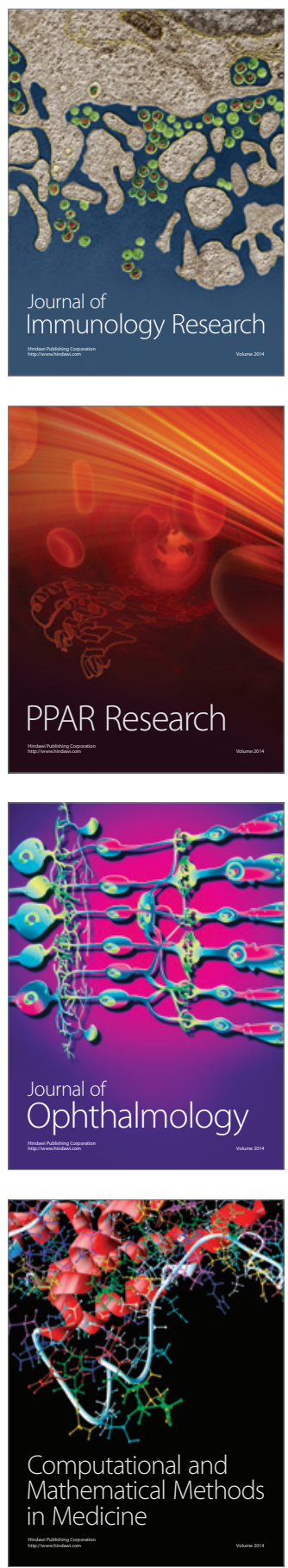

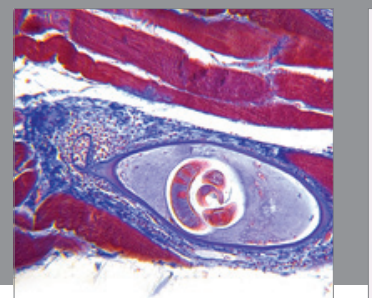

Gastroenterology

Research and Practice
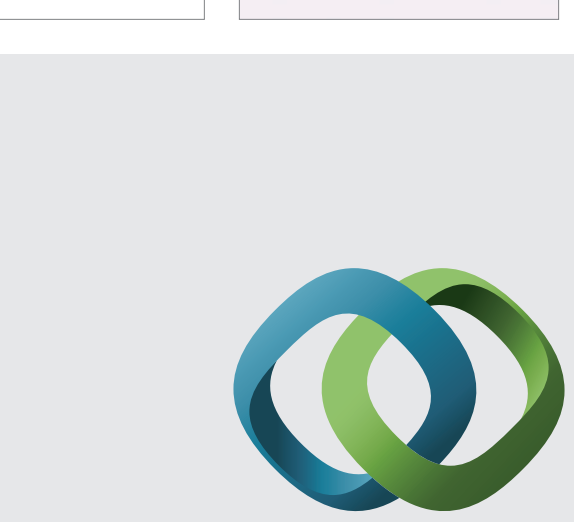

\section{Hindawi}

Submit your manuscripts at

http://www.hindawi.com
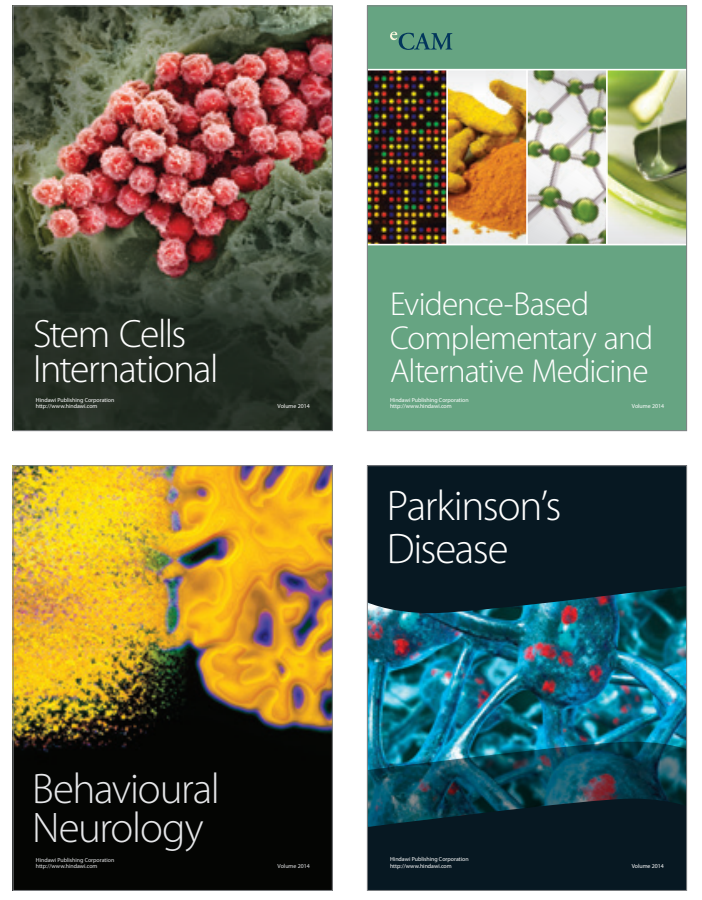
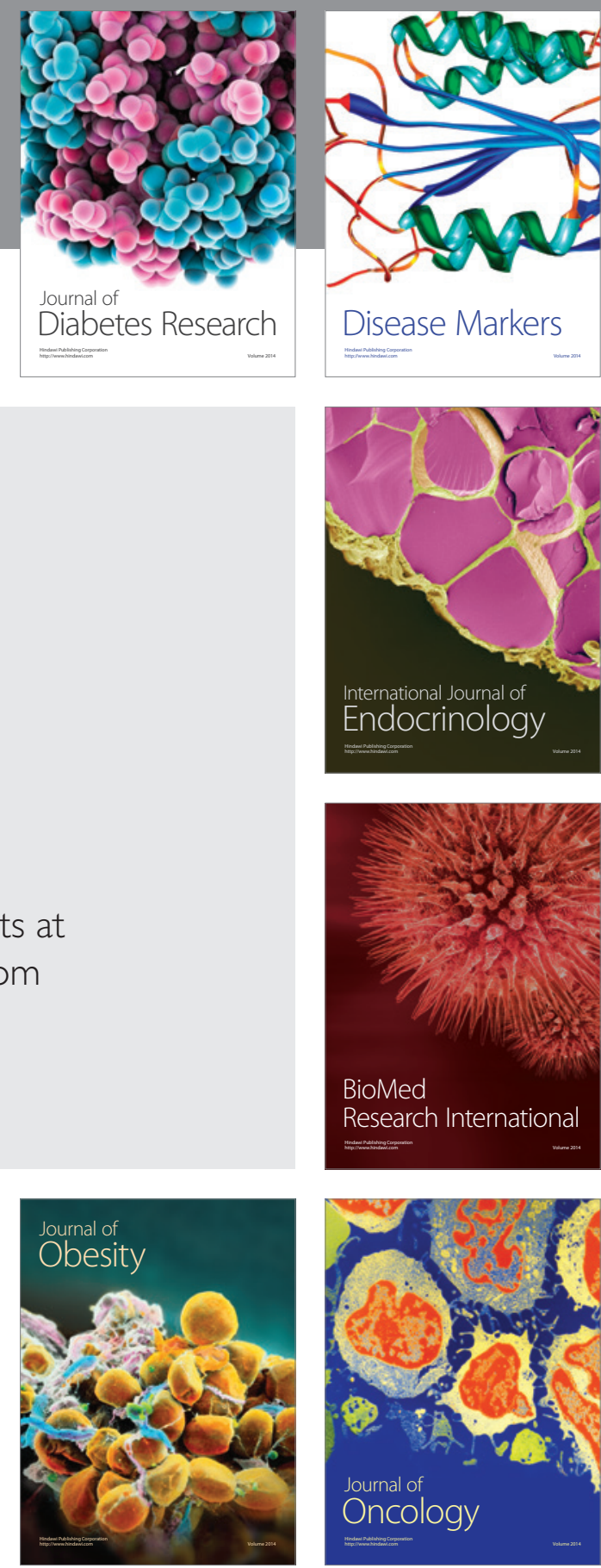

Disease Markers
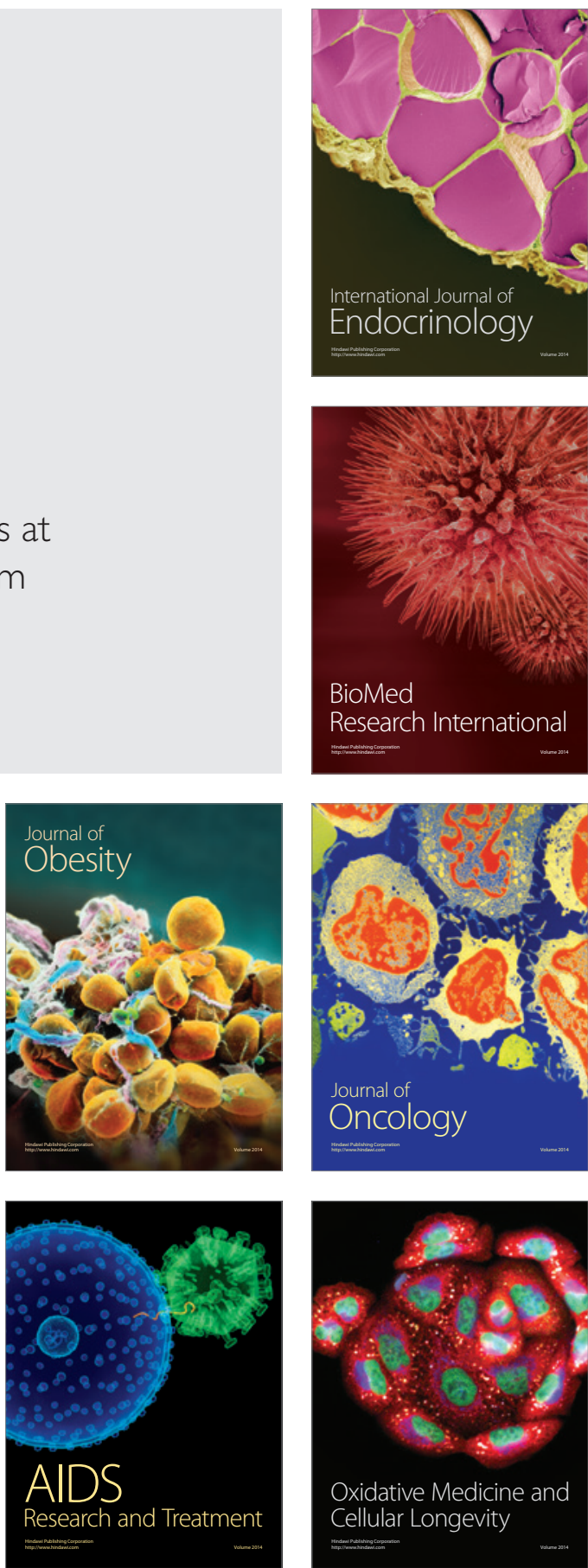